\title{
Carbonic Anhydrase: A New Therapeutic Target for Managing Diabetes
}

Ibrahim S Ismail*, Ameh D Amodu, Atawodi S Ene-ojoh and Umar I Alhaji

Department of Biochemistry, Ahmadu Bello University Zaria, Nigeria

\begin{abstract}
Background: Carbonic Anhydrase (CA) is a zinc metallo-enzyme that is critical to regulation of systemic acid-base homeostasis by facilitating urinary acidification. Inhibition of carbonic anhydrase results in metabolic acidosis which leads to decrease in $\mathrm{pH}$.
\end{abstract}

Aim and objectives: The study aims to highlight the potential utility of erythrocyte carbonic anhydrase as therapeutic target for managing diabetes, by investigating changes of erythrocyte carbonic anhydrase activity in STZ induced diabetic rats.

Methods: Carbonic anhydrase activity was determined by the absorbance of $p$-nitrophenol at $345 \mathrm{~nm}$ released from p-nitrophenyl acetate. HbA1c was determined by ion exchange method (Spectrum diagnostics). Biochemical parameters were determined by Accutrend GCT meters with cobias ${ }^{\circledR}$ test strips.

Results: The result revealed that inhibition of erythrocyte carbonic anhydrase results in significant increase in both blood lactate concentration and $\mathrm{HbA} 1 \mathrm{c}$ level with significant reduction in blood glucose concentration. Metformin was found to reduce carbonic anhydrase activity and $\mathrm{HbA} 1 \mathrm{c}$ level significantly and increased blood lactate concentration. The extract of Cadaba farinosa was found to reduce blood glucose concentration.

Conclusions: Inhibition of carbonic anhydrase can be associated with reduced circulating blood glucose level. Metformin may therefore reduce circulating blood glucose by inhibiting carbonic anhydrase. Increased level of $\mathrm{HbA} 1 \mathrm{c}$ may probably be due to inhibition of erythrocyte carbonic anhydrase. Therefore Carbonic anhydrase can potentially serve as a therapeutic target for managing diabetes in combination as serving as valuable marker for lactic acidosis.

Keywords: Carbonic anhydrase; HbAlc; Lactate; Diabetes; Metformin; Cadaba farinose

\section{Introduction}

Carbonic anhydrases (CAs) are ubiquitous zinc metalloenzymes that primarily catalyze the reversible hydration of carbon dioxide to form bicarbonate and protons, a reversible reaction that occurs relatively slowly in the absence of a catalyst $[1,2]$. Several important physiological and pathological functions are played by the CA isozymes present in organisms, this includes transport of $\mathrm{CO}_{2}$ and ions (such as $\mathrm{H}^{+}, \mathrm{Na}^{+}$and $\mathrm{Cl}^{-}$) along with $\mathrm{pH}$-regulation in a variety of physiological processes ranging from respiration to intermediary metabolism at the cellular level $[3,4]$. These enzymes play very important role in providing bicarbonate as substrate for carboxylation in different essential metabolic pathways which include gluconeogenesis and synthesis of some amino acids (pyruvate carboxylase) lipogenesis (pyruvate carboxylase and acetyl coA carboxylase), ureagenesis (carbamoyl synthase I) and pyrimidine synthesis (Carbamoyl phosphate synthase II) [5]. Carbonic anhydrase is found in the blood of all vertebrates. Some early evidences suggest that the changes in carbonic anhydrases activities in erythrocytes may be an initial step of altered metabolism in diabetes mellitus [6]. However, the precise role of Carbonic anhydrase activity, in the development of diabetes mellitus, is currently unknown. It has been reported that inhibition of Carbonic anhydrase was found to impair proton secretion into the proximal tubule lumen and thereby decreased bicarbonate reabsorbtion and rate of acidification of urine, producing alkaline urine and eventually metabolic acidosis [7]. Carbonic anhydrase inhibitors are widely used in clinical practice as diuretics and antihypertensive drugs [8]. Recent studies showed that carbonic anhydrase inhibitors may provide a novel therapy for obesity, cancer, infection and Alzheimer's disease. However, as carbonic anhydrase are ubiquitous enzymes in vertebrates, carbonic anhydrase inhibition in organs other than the target may result in undesired side effects. The most frequent ones are: numbness and tingling of extremities; metallic taste; depression; fatigue; malaise; weight loss; decreased libido; gastrointestinal irritation; metabolic acidosis; renal calculi and transient myopia [9-12], which are all common among diabetic patients.

Metabolic acidosis is the most common serious acid-base disorder complicating diabetes mellitus. Metabolic acidosis is associated with increased mortality [13]. Lactic acidosis results in higher mortality than metabolic acidosis of a different etiology [14]. Lactic acidosis is an alarming metabolic signal of many pathological states, and endogenous clearance of lactate is a commonly used prognostic marker of illness [15]. When glucose disposal is stimulated with insulin, plasma lactate concentration increases and the concentration is positively correlated with the rate of glucose disposal [16]. In STZ induced diabetes (which is a model of type 1 diabetes) resting blood lactate is reported to be elevated $[17,18]$, and STZ induced diabetes in rats has also been found to decrease skeletal muscle lactate transport [17]. Studies have shown that mono-carboxylate transporters (MCT) dependent lactate- $\mathrm{H}^{+}$ flux is facilitated by bicarbonate transporters and carbonic anhydrase enzyme in various cells and tissue [19,20]. Accumulating evidence implicates changes in carbonic anhydrase activity in diabetes. This notion has not been adequately studied. Our present study aimed to study these changes and to highlight the potential usage of carbonic anhydrase as a new enzyme therapeutic target for managing diabetes;

*Corresponding author: Ibrahim Salihu Ismail, Department of Biochemistry Ahmadu Bello University Zaria, Nigeria, Tel: +2348036316108; E-mail: salihuringim@yahoo.com

Received December 29, 2015; Accepted January 11, 2016; Published January 18, 2016

Citation: Ibrahim SI, Ameh DA, Atawodi SE, Umar IA (2016) Carbonic Anhydrase: A New Therapeutic Target for Managing Diabetes. J Metabolic Synd 5: 196 doi:10.4172/2167-0943.1000196

Copyright: (c) 2016 Ibrahim SI, et al. This is an open-access article distributed under the terms of the Creative Commons Attribution License, which permits unrestricted use, distribution, and reproduction in any medium, provided the original author and source are credited. 
by analyzing changes in erythrocyte carbonic anhydrase activity in uncontrolled and treated STZ induced diabetic rats.

\section{Materials and Methods}

\section{Preparation of extract of cadaba farinosa leaves}

Cadaba farinosa leaves were collected and authenticated at the Biological science Department of Ahmadu Bello University Zaria, Nigeria. A voucher number was given as no. 2744 and was deposited at the herbarium of the department. The leaves were, washed, air-dried at room temperature, grinded to powder. The crude extract was obtained through successive soxhlet extraction by dissolving $800 \mathrm{~g}$ of powdered plant leaves in $2.5 \mathrm{~L}$ of $\mathrm{n}$-Hexane followed by ethyl acetate and finally methanol for 48 hours each in a soxhlet apparatus. The crude fractions were concentrated using rotary evaporator and stored in a dessicator until use.

\section{Study animals}

Male Wister albino rats of $180-220$ grams weight were used for this study. Before initiation, the rats were allowed acclimatization period of 7 days in laboratory condition. Five rats each were housed in polycarbonate cages bedding with husk, 20 to $24^{\circ} \mathrm{C}$ temperature and relative humidity between 30 to 70 percent. The dark and light cycle of 12 hours each was maintained. Standard animal diet with pure water in glass bottles ad libitum were fed to the animals. The principles of laboratory animal care were followed according to the instructions by the Institutional Animal Ethics Committee.

Induction of diabetes: Diabetes was induced in all the rats except in the normal controls (Group I) by Streptozotocin(STZ) $60 \mathrm{mg}$ per $\mathrm{kg}$ body weight, dissolved in ice cold citrate buffer $(0.1 \mathrm{M}, \mathrm{pH} 4.5)$, through intraperitoneal route. Hyperglycemia was confirmed by elevated fasting glucose level $>200 \mathrm{mg} / \mathrm{dl}$ in plasma, determined at 72 $\mathrm{h}$ after injection. Hyperglycemic rats were included for the study along with the normal control animals.

Study design: The animals were grouped into five groups of five rats each. Group I rats (Normal control); Group II (Diabetic control); Group III (Diabetic rats treated with Acetazolamide, $250 \mathrm{mg} / \mathrm{kg} / \mathrm{day}$ for 28 days); Group IV (Diabetic rats treated with Metformin, $500 \mathrm{mg} /$ $\mathrm{kg} /$ day for 28 days) and Group V (Diabetic rats treated with methanol extract of Cadaba farinosa leaves $1 \mathrm{~g} / \mathrm{kg} /$ day for 28 days). Both animals were fed with standard animal feed mentioned above and distilled water. But Group I (Normal control) and Group II (Diabetic control) rats received only water at the time of treatment of other groups.

Collection and preparation of samples: The blood samples were collected by cardiac puncture in vials with EDTA and centrifuged at $3500 \mathrm{rpm}$ for 10 minutes. The plasma was separated from the cells and buffy coat removed. The packed red cells were washed three times with normal saline $(0.9 \% \mathrm{NaCl})$ and were lysed with ice cold water, yielding destroyed plasma membranes.

\section{Biochemical analysis}

Metabolic parameters: Blood glucose, lactate, cholesterol and triglycerides levels were measured using (Accutrend GCT Meter, Roche, Germany with Cobas test strips)

Glycosylated haemoglobin determination: $\mathrm{HbAlc}$ was estimated by ion exchange methods using standard reagent kits, according to the manufacturers' instruction, (Spectrum-diagnostics, Egypt).
Assay of carbonic anhydrase activity: Carbonic anhydrase activity was determined as mentioned by [21], with the modification described by [22] using spectrophotometer. In this assay, the esterase activity of carbonic anhydrase was determined from the hydrolysis rate of $3 \mathrm{mM}$ p-nitrophenyl acetate to p-nitrophenol. The assay system contained $100 \mu \mathrm{L}$ hemolysate placed in $1 \mathrm{~cm}$ spectrometric cell containing $1.4 \mathrm{ml}$ $0.05 \mathrm{M}$ Tris- $\mathrm{HCl}$ buffer, $\mathrm{pH}: 7.4$ and $1.5 \mathrm{ml}$ p-nitrophenyl acetate. The change in absorbance at $348 \mathrm{~nm}$ was measured over the period of $3 \mathrm{~min}$ before and after adding the sample. The absorbance was measured by a UV-Vis spectrophotometer (Shimadzu UV-2600 Spectrophotometer). One unit of enzyme activity was expressed as $\mu \mathrm{mol}$ of $\mathrm{p}$-nitrophenol relased $/ \mathrm{min} / \mu \mathrm{L}$ from hemolysate at room temperature $\left(25^{\circ} \mathrm{C}\right)[6,23]$.

Statistical analysis: Results were presented as mean \pm standard Deviation (SD). Within and between groups, comparisons were performed by the analysis of variance (ANOVA) (using SPSS 20.0 for windows Computer Software Package). Significant differences were compared by Duncan's new Multiple Range test; a probability level of less than 5\% $(P<0.05)$ was considered significant.

\section{Results}

\section{Acetazolamide reduces blood glucose; increases blood lactate and $\mathrm{HbA1c}$ level in STZ induced diabetic rats}

We examined whether inhibition of carbonic anhydrase in STZ induced diabetic rats affects blood glucose, blood lactate and HbAlc level. Acetazolamide treated STZ induced diabetic rats at $250 \mathrm{mg} / \mathrm{kg} /$ day for 28 days resulted in 3 fold significant $(p<0.05)$ increase in HbAlc when compared with normal control rats (Figure 1). Blood lactate was also significantly $(\mathrm{p}<0.05)$ increased 4 fold in STZ induced diabetic rats treated with Acetazolamide when compared with normal control (Figure 2). Blood glucose level reduced significantly $(\mathrm{p}<0.05)$ in STZ induced diabetic rats treated with acetazolamide when compared with normal control (Figure 3).

\section{Metformin suppresses carbonic anhydrase activity; increases blood lactate and reduces $\mathrm{HbAlc}$ level in STZ induced diabetic rats}

We treated STZ induced diabetic rats with Metformin $1000 \mathrm{mg} / \mathrm{kg} /$ day for 28 days. Significant $(\mathrm{p}<0.05)$ reduction in both blood glucose and $\mathrm{HbAlc}$ level was observed when compared with normal control (Figure 3). Metformin also significantly $(\mathrm{p}<0.05)$ reduces carbonic anhydrase activity when compared with normal control (Figure 4).

Cadaba farinosa extract lowers blood glucose and glycated hemoglobin (HbA1c) level in STZ induced diabetic rats: To investigate the effect of crude methanol extract of Cadaba farinosa on STZ induced diabetic rats, the level of glucose and HbAlc were measured. The extract $(1000 \mathrm{mg} / \mathrm{kg} /$ day for 28 days $)$ significantly $(p<0.05)$ reduces the level of blood glucose and HbAlc level when compared with diabetic control (Figure 2 and 3 ). Though, the reduction of $\mathrm{HbAlc}$ was not significant when compared with the diabetic control (Figure 1).

Cadaba farinosa extract affects carbonic anhydrase activity and blood lactate level in STZ induced diabetic rats: We examined whether cadaba farinosa crude methanol extract affect carbonic anhydrase activity in the erythrocytes of STZ induced diabetic rats. The result showed a significant $(\mathrm{p}<0.05)$ reduction in carbonic anhydrase activity of the extract treated STZ induced diabetic rat when compared with normal control but a significant $(\mathrm{p}<0.05)$ increase in carbonic anhydrase activity was observed when compared with 


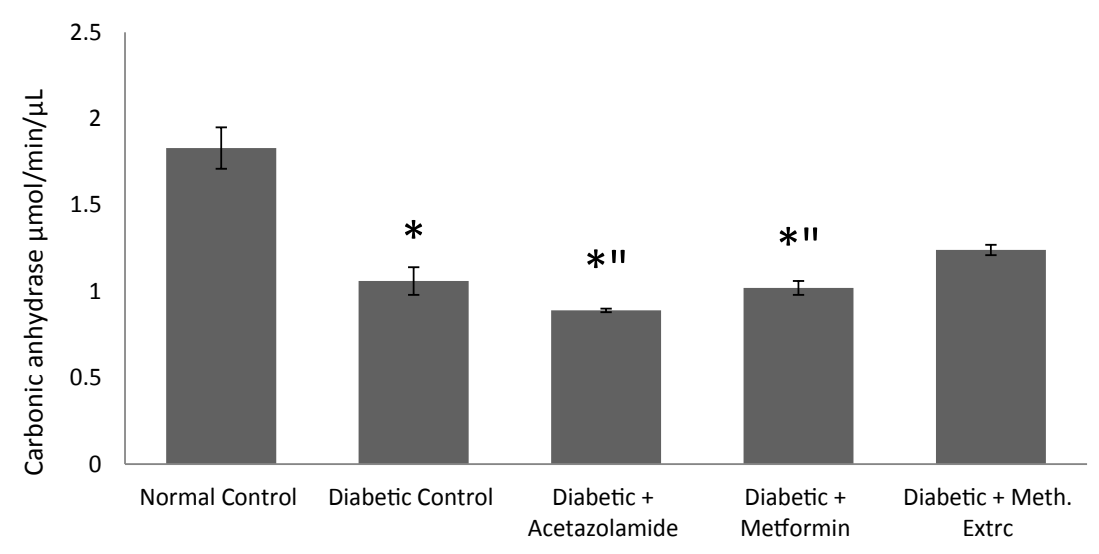

Figure 1: The effect of Acetazolamide, Metformin and Methanol extract of Cadaba farinosa on carbonic anhydrase activity levels in STZ induced diabetic rats treated at $250 \mathrm{mg} / \mathrm{kg} /$ day, $500 \mathrm{mg} / \mathrm{kg} /$ day and $1000 \mathrm{mg} / \mathrm{kg} /$ day doses for 28 days. ${ }^{*} P<0.05 \mathrm{vs}$. Normal control; " $P<0.05$ vs. Diabetic control ( $\mathrm{n}=5$ ).

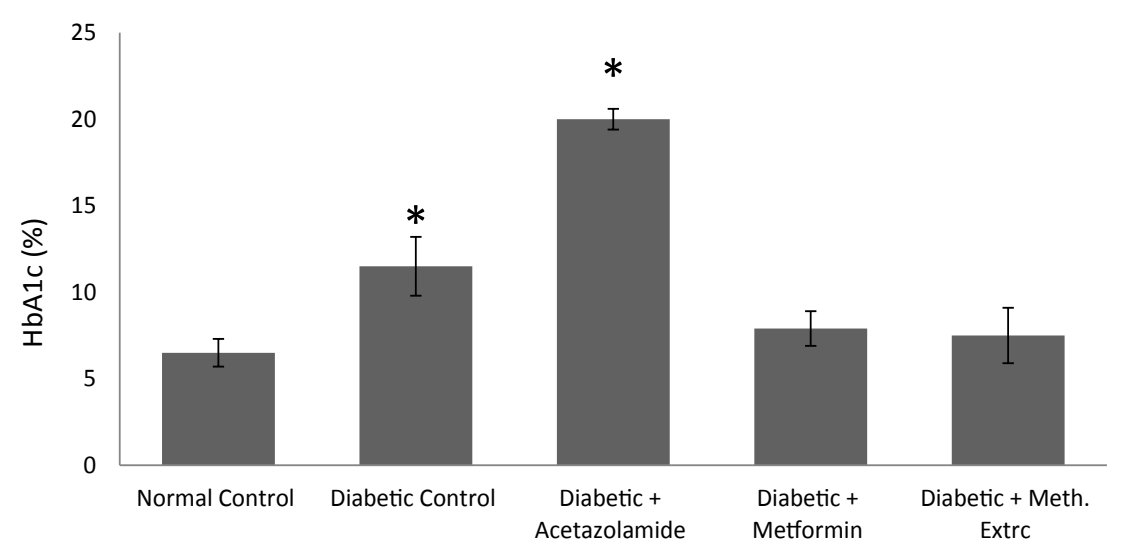

Figure 2: The effect of Acetazolamide, Metformin and Methanol extract of Cadaba farinosa on HBA levels in STZ induced diabetic rats treated at $250 \mathrm{mg} / \mathrm{kg} / \mathrm{day}$ $500 \mathrm{mg} / \mathrm{kg} /$ day and $1000 \mathrm{mg} / \mathrm{kg} /$ day doses for 28 days. ${ }^{*} \mathrm{P}<0.05 \mathrm{vs}$. Normal control; " $P<0.05$ vs. Diabetic control $(n=5)$.

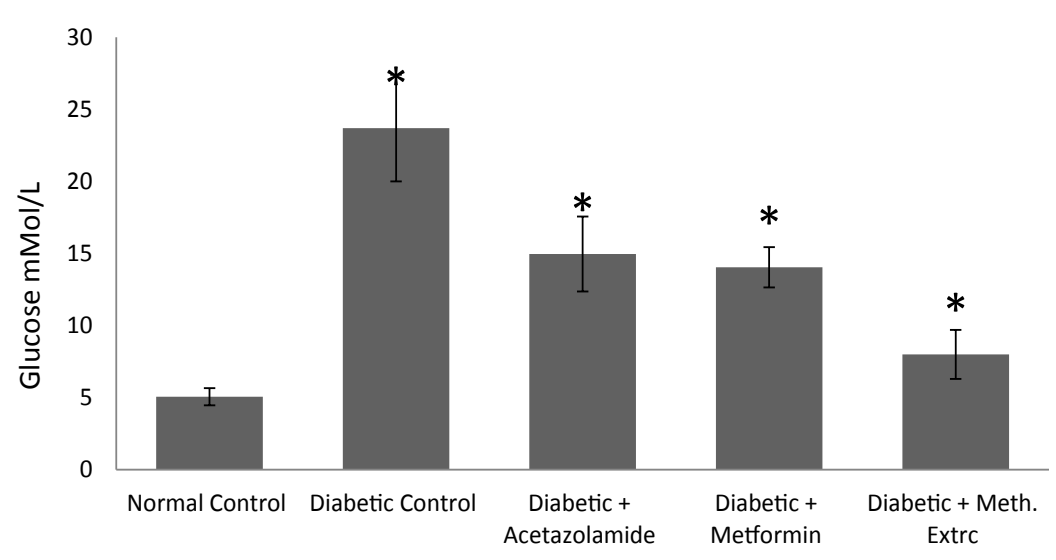

Figure 3: The effect of Acetazolamide, Metformin and Methanol extract of Cadaba farinosa on Glucose levels in STZ induced diabetic rats treated at $250 \mathrm{mg} / \mathrm{kg} / \mathrm{day}$, $500 \mathrm{mg} / \mathrm{kg} /$ day and $1000 \mathrm{mg} / \mathrm{kg} /$ day doses for 28 days. ${ }^{*} \mathrm{P}<0.05 \mathrm{vs}$. Normal control; " $\mathrm{P}<0.05$ vs. Diabetic control $(\mathrm{n}=5)$.

uncontrolled diabetic control (Figure 4). Even though the change in lactate concentration was not significant when compared with both the normal and diabetic control, but lactate level increases in the extract treated diabetic group when compared with normal control and decreases when compared with diabetic control (Figure 2).

\section{Acetazolamide, Metformin and Cadaba farinosa extract also affect blood cholesterol and Triglycerides levels in STZ induced diabetic rats}

Figure 5 indicates, Acetazolamide and Metformin significantly $(\mathrm{p}<0.05)$ reduced blood cholesterol level (Figures 5 and 6$)$, while blood 


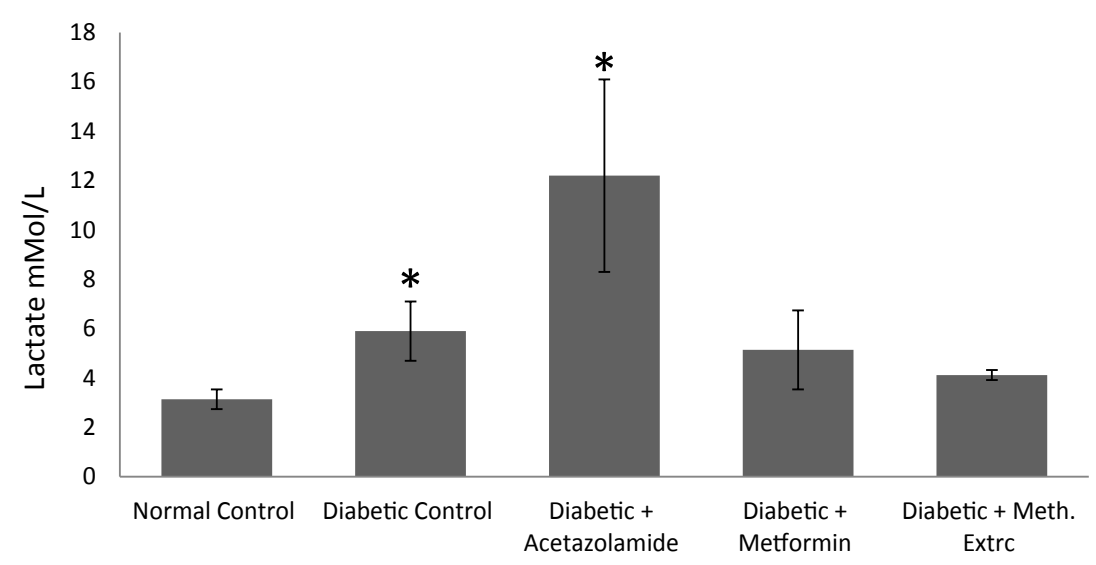

Figure 4: The effect of Acetazolamide, Metformin and Methanol extract of Cadaba farinosa on Lactate levels in STZ induced diabetic rats treated at $250 \mathrm{mg} / \mathrm{kg} / \mathrm{day}$, $500 \mathrm{mg} / \mathrm{kg} /$ day and $1000 \mathrm{mg} / \mathrm{kg} /$ day doses for 28 days. ${ }^{*} \mathrm{P}<0.05 \mathrm{vs}$. Normal control, $(\mathrm{n}=5)$.

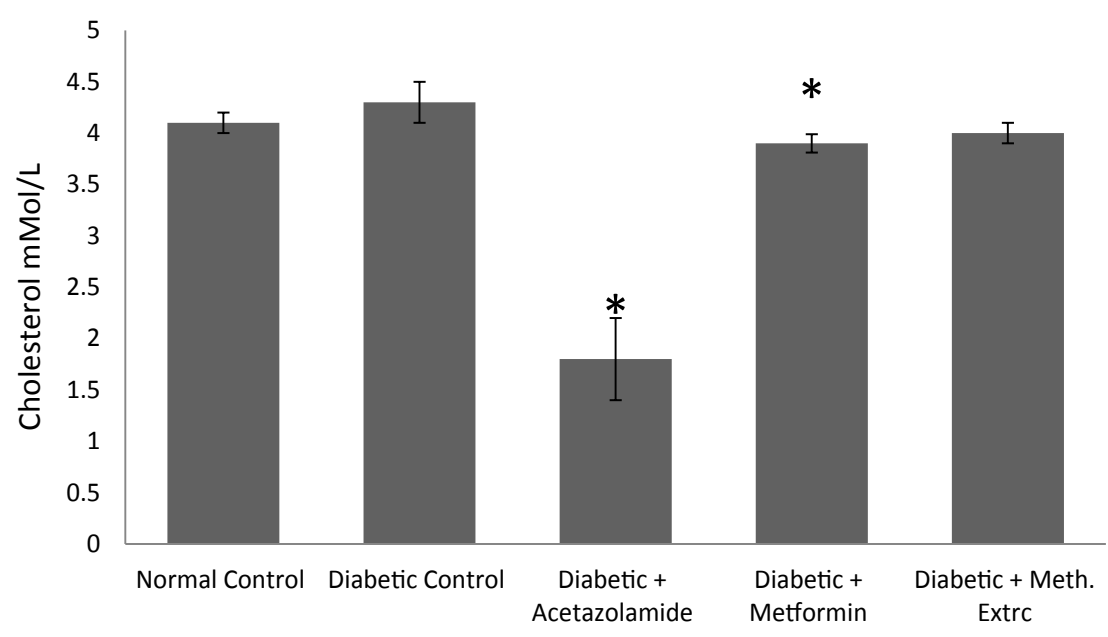

Figure 5: The effect of Acetazolamide, Metformin and Methanol extract of Cadaba farinosa on Cholesterol levels in STZ induced diabetic rats treated at $250 \mathrm{mg} / \mathrm{kg} /$ day, $500 \mathrm{mg} / \mathrm{kg} /$ day and $1000 \mathrm{mg} / \mathrm{kg} /$ day doses for 28 days. ${ }^{*} \mathrm{P}<0.05 \mathrm{vs}$. Normal control, $(\mathrm{n}=5)$.

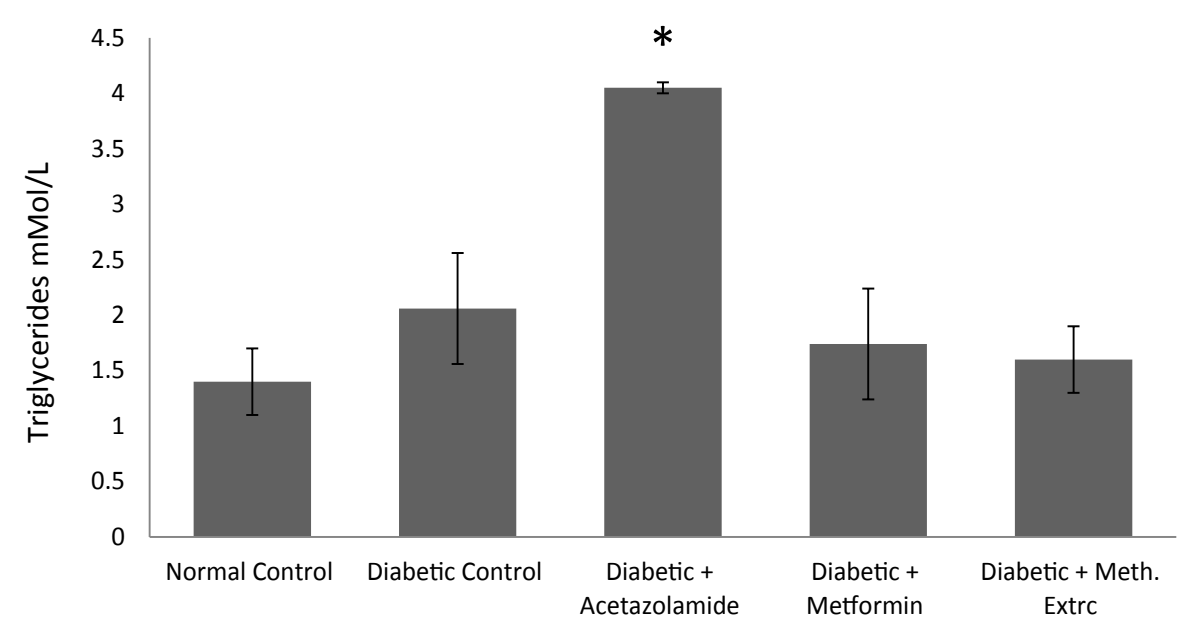

Figure 6: The effect of Acetazolamide, Metformin and Methanol extract of Cadaba farinosa on Triglycerides levels in STZ induced diabetic rats treated at $250 \mathrm{mg} / \mathrm{kg} /$ day, $500 \mathrm{mg} / \mathrm{kg} /$ day and $1000 \mathrm{mg} / \mathrm{kg} /$ day doses for 28 days. ${ }^{*} \mathrm{P}<0.05 \mathrm{vs}$. Normal control, $(\mathrm{n}=5)$. 
triglycerides level increased significantly $(\mathrm{p}<0.05)$ under the effect of Acetazolamide (Figure 6).

\section{Discussion}

Our present research findings demonstrated that, prolonged untreated diabetes result in decreased carbonic anhydrase activity. [23] previously examined the changes in the activity of CA-III in hepatocytes of acute diabetic rats. Diabetes resulted in 50\% reduction in the activity of CA-III. They also observed an approx. $98 \%$ reduction in CA-III content in the liver of chronic diabetes mellitus rats relative to controls. A 75\% reduction in serum CA-III content was observed relative to control values after the administration of streptozotocin. The increased blood lactate level observed in the present study is consistent with the findings of $[24,25]$ who showed that lactate is not only increased in the early stages of diabetes but has also been shown to predict its occurrence in the future. Forbath and De Meutter [26,27], had also reported that there is an increase in lactate production, in diabetic dogs and humans.

We investigated the role of carbonic anhydrase activity in diabetes by inhibiting the enzyme with a known inhibitor (Acetazolamide), and interestingly we found out that carbonic anhydrase inhibition in STZ induced diabetic rats' lowers blood glucose level. Previous published studies have provided mixed results regarding the potential of carbonic anhydrase inhibitors to modulate blood glucose levels. Acetazolamide and ethoxyzolamide were found to inhibit gluconeogenesis in vitro or after acute administration in rats [28-30]. [28] concluded that carbonic anhydrase is functionally important for gluconeogenesis in the male guinea pig liver when there is a requirement for bicarbonate as substrate. We may therefore suggest that carbonic anhydrase plays a crucial role in gluconeogenesis, due to the fact that carbonic anhydrase inhibition does not only lowers blood glucose level but increases blood lactate level as well. Many studies have demonstrated that suppression of hepatic gluconeogenesis is accompanied by increased blood lactate level as seen in metformin treatment of type II diabetes. High therapeutic metformin levels provoked a reduction in lactate uptake by the liver [31]. A potentially life-threatening complication of Metformin is the occurrence of lactic acidosis, metformin-associated lactic acidosis (MALA). To reproduce the result, we treated STZ induced diabetic rats with Metformin $500 \mathrm{mg} / \mathrm{kg} /$ day for 28 days in order to investigate the effect of Metformin on carbonic anhydrase activity and blood lactate level. For the first time our present study demonstrates that Metformin significantly $(\mathrm{p}<0.05)$ reduced carbonic anhydrase activity and increased blood lactate level.

However, the magnitude of the efflux of lactate into the bloodstream, which is the anionic form of lactic acid, may override the body's ability to utilize protons, hence converting hyperlactatemia into lactic acidosis. Indeed, it has been proposed that increased muscle release of lactate and alanine could be responsible for sustaining increased gluconeogenesis in NIDDM [32]. Since increased provision of lactate is of considerable importance for the increased gluconeogenesis found in diabetes. Similarly, carbonic anhydrase has been found to facilitate lactic acid transport in rat skeletal muscle fibers [33]. It's also reported that MCT1 and MCT4 transport activity is increased by interaction with carbonic anhydrase II (CAII) [20,34,35]. Since monocarboxylate (MCT) dependent lactate- $\mathrm{H}^{+}$flux is facilitated by bicarbonate transporters and carbonic anhydrase activity in various cells and tissues [33-37]. We may therefore report that inhibition of carbonic anhydrase may impair lactate flux across the MCT's in various cells and tissues. We may therefore suggest that the reported incidence of lactic acidosis that occur with Metformin therapy in type II diabetes might be the result of suppressed carbonic anhydrase activity.
It has been stated previously that the activity of carbonic anhydrase has reduced significantly in the liver of both acute and chronic streptozotocin induced diabetic rats. The ability of Metformin to inhibit carbonic anhydrase in diabetic rats points towards a negative change that indicates a powerful effect on aspects of the complex metabolic disturbance in diabetes. Therefore carbonic anhydrase could be a new enzymatic therapeutic target for managing diabetes.

The ability of metformin to lower circulating blood glucose levels in type II diabetic patients can be explained by various mechanisms, such as increased glucose uptake in liver and muscle, reduced gluconeogenesis, decreased lactate and alanine uptake, improved GLP-1 and reduced glucagon functions. Nevertheless, the molecular principles of metformin action remain debated.

The overall effect of the metformin action is that, metformin inhibits gluconeogenic enzymes and stimulates glycolysis by altering the activity of multiple enzymes in gluconeogenesis, glycogenolysis, ketogenesis and $\beta$-Oxidation pathways [38]. Gluconeogenesis accounts for $28-97 \%$ of overall hepatic glucose output depending on the feeding status in nondiabetic individuals, the rate being higher in patients with advanced type 2 diabetes mellitus [39]. Metformin was reported to reduce hepatic glucose output by up to $75 \%$ [40].

The uptake of gluconeogenic substrates, such as alanine and lactate, is reduced in the presence of metformin [41]. The effects of metformin on hepatic glycogen metabolism are not well-established; however, in vitro treatment of hepatocytes decreased glycogen synthesis [42]. With these various unestablished proposed mechanisms of metformin action, we may therefore propose that metformin reduces circulating blood glucose level due to inhibition of carbonic anhydrase, which facilitate lactate (a gluconeogenic substrate) uptake by the hepatocytes for the synthesis of glucose.

Metahonl leaf extract of Cadaba farinosa, lowers blood glucose level significantly $(\mathrm{p}<0.05)$ in STZ induced diabetic rats when compared with diabetic control. This similar trend has been observed with metformin treatment, an established hypoglycemic agent. Leaf extract of Cadaba farinosa is being used for the treatment of cancer and diabetes in some parts of northern Nigeria as folk medicine. We demonstrated for the first time that Cadaba farinosa methanol leaf extract has aminonitrile containing compounds from the FTIR spectra analysis, which showed absorption characteristic bands related to $\alpha$ aminonitrile at $2226.31 \mathrm{~cm}^{-1}$ region which is tentatively assigned to Nitrile group $(\mathrm{C} \equiv N)$ (Data not shown here). Several amino nitriles have been developed as reversible inhibitors of dipeptidyl peptidase (DPP IV) for treating diabetes [43]. Vildagliptin is a recently released aminonitrile-containing antidiabetic drug that inhibits dipeptidyl peptidase IV (DPP-IV). We suggest that, the reduction in blood glucose level may be due to the presence of aminonitrile containing compounds in the leaves, but further research is required on the plant.

Moreover, our study also demonstrates relationship of carbonic anhydrase inhibition with dyslipidemia. Our results show significant decrease in total cholesterol $(\mathrm{p}<0.05)$, and significant increase in triglyceride $(\mathrm{p}<0.05)$ in STZ induced diabetic rats treated with Acetazolamide. Dyslipidemia is a common finding in diabetes mellitus. Diabetic dyslipidemia is associated with high plasma triglycerides, low HDL-Cholesterol and increased small dense LDL-Cholesterol particles [44]. Hypertriglyceridemia is more common in diabetics as compared to non-diabetics due to four (4) fold increase in VLDL triglyceride [45]. Our result is consistent with the findings above. Previous study reported the role of carbonic anhydrase in hepatic lipogenesis at the level of pyruvate carboxylation [46] and their role in providing bicarbonate as 
substrate for carboxylation in lipogenesis (pyruvate carboxylase and acetyl coA carboxylase), [5]. If truly carbonic anhydrase is associated with lipogenesis, it's therefore not surprising the changes seen in the level of cholesterol and triglyceride.

The results of the present study showed a 3 fold significant $(\mathrm{p}<0.05)$ increase in $\mathrm{HbAlc}$ level (Figure 2) in STZ induced diabetic rats treated with carbonic anhydrase inhibitor (Acetazolamide). This increase was exclusively as a result of direct inhibition of carbonic anhydrase invivo. Carbonic anhydrase has been associated with altered metabolism, because carbonic anhydrase is a $\mathrm{pH}$-regulatory enzyme in most of the tissues including erythrocytes [22,47]. It has been reported that inhibition of carbonic anhydrase was found to impair proton secretion and eventually metabolic acidosis [7]. Metabolic acidosis results in decreased $\mathrm{pH}$ level. Several factors have been reported that can influence the rate of glycation of hemoglobin: which are $\mathrm{pH}$ [48-50], glucose concentration [48], carbonate [51] and catalysis by 2, 3-diphosphoglycerate [49,52,53] In 1958 [54] published a paper describing the heterogeneity of haemoglobin A. The hemoglobin fractions that eluted at more acidic $\mathrm{pH}$ on the anion exchanger carboxy methylcellulose and migrated more rapidly on electrophoresis were called minor haemoglobins or fast haemoglobins. Which could be sub fractionated into the species A (1a), A(1b), A(1c), A(1d). Later this fast haemoglobin was identified as Allen's HbAlc and the charge difference localised to the $\beta$ chain [55]. Low intracellular $\mathrm{pH}$ (pHi) has been reported to increase glycation of hemoglobin as $\mathrm{pH}$ levels within the erythrocyte can increase (low erythrocyte $\mathrm{pH}$ ) or decrease (high erythrocyte $\mathrm{pH}$ ) $\mathrm{HbAl}$ c formation [56]. We may therefore suggest that, the increased $\mathrm{HbAlc}$ level seen in diabetes may be attributed to the increased anaerobic glycolysis in erythrocyte which produces lactate as the end product of glycolysis. Red blood cells produce lactic acid as a byproduct of the regeneration of ATP during anaerobic glycolysis but cannot use lactic acid [57]. The rate of production can increase 50 -fold if either glucose or glycogen is required to generate ATP in the absence of oxygen [57]. Lactate is transported out of the cell via monocarboxylate transporters (MCT) in an electroneutral transport mode of $1 \mathrm{H}^{+}$: 1 Lactate [58].

$\mathrm{H}^{+}$transport system under conditions of exclusively aerobic metabolism is used by the cell to maintain a facilitation of $\mathrm{CO}_{2}$ diffusion, whereas under conditions of dominating anaerobic glycolysis and low intracellular $\mathrm{pH}$, it is mainly used to transport $\mathrm{H}^{+}$along with the lactate anion through the monocarboxylate transporters (MCT), a prerequisite for the elimination of lactic acid from the cell. Inhibition of carbonic anhydrase may result in increased intracellular lactate level as has been previously shown, which will lead to lactic acidosis and consequently decreased intracellular $\mathrm{pH} i$. The presence of carbonic anhydrase significantly buffers $\mathrm{pH} i$, on the other hand disruption of $\mathrm{pH} i$ via inhibition of Carbonic anhydrase may decrease lactate efflux and result in intracellular lactate accumulation which decreased $\mathrm{pH} i$, and enhence increased $\mathrm{HbAlc}$ formation.

If what [56] reported is true, then we may conclude that inhibition of intracellular erythrocyte carbonic anhydrase will lead to accumulation of intracellular lactate and result in lactic acidosis which brings about decreased $\mathrm{pH}(\mathrm{pH} i)$. At a low $\mathrm{pH}$ even glucose cannot be utilized anaerobically due to the fact that cellular energy production can be compromised in metabolic acidosis [59] as the activity of 6-phosphofructokinase, a critical enzyme in glycolysis, is $\mathrm{pH}$ dependent. The net effect is increased formation of $\mathrm{HbA} 1 \mathrm{c}$ favored by low $\mathrm{pH}$ and continues supply of glucose to erythrocytes due to mass action effect; and also due to blockage of further oxidation of glucose to lactate to prevent further drop in $\mathrm{pH}$.
We concluded that inhibition of carbonic anhydrase can be associated with reduced circulating blood glucose level. Metformin may therefore reduce circulating blood glucose by inhibiting carbonic anhydrase. Cadaba farinosa leaf extract reduces blood glucose level probably by its action on dipeptidyl peptidase IV due to the presence of aminonitrile containing compounds. Increased level of HbAlc may probably be due to inhibition of erythrocyte carbonic anhydrase which lead to decreased $\mathrm{pH}$ level.

\section{Acknowledgments}

We thank the staff of Animal house, Aliyu, and Salihu for their excellent technical help; and Dr. Auwal Ibrahim for editorial assistance.

\section{References}

1. Supuran CT (2007) Carbonic anhydrases as drug targets--an overview. Curr Top Med Chem 7: 825-833.

2. Carter MJ, Parsons DS (1971) The Isoenzymes of Carbonic Anhydrase: Tissue, subcellular Distribution and Functional Significance, with Particular Reference to the Intestinal Tract. J Physiol 215: 71-94.

3. Henry RP (1996) Multiple roles of carbonic anhydrase in cellular transport and metabolism. Annu Rev Physiol 58: 523-538.

4. Zanconato S, Cooper DM, Armon Y, Epstein S (1992) Effect of increased metabolic rate on oxygen isotopic fractionation. Respiration Physiology 89 319-327.

5. Chegwidden WR, Dodgson SJ, Spencer IM (2000) The roles of carbonic anhydrase in metabolism, cell growth and cancer in animals. EXS: 343-363.

6. Gambhir KK, Oates P, Verma M, Temam S, Cheatham W (1997) High fructose feeding enhances erythrocyte carbonic anhydrase 1 mRNA levels in rat. Ann N Y Acad Sci 827: 163-169.

7. Hannedoeche T, Lazaro M, Delgado AG, Boitard C, Lacour B, et al. (1991) Feedback-mediated reduction in glomerular filtration during acetazolamide infusion in insulin-dependent diabetic patients. Clin Sci 81: 457-464.

8. Pastorekova S, Parkkila S, Pastorek J, Supuran CT (2004) Carbonic anhydrases: current state of the art, therapeutic applications and future prospects. J Enzyme Inhib Med Chem 19: 199-229.

9. Bartlett JD, Jaanus SD (1989) Clinical ocular pharmacology. Elsevier Inc, Butterworth, Boston, USA.

10. Maren TH (1992) Role of carbonic anhydrase in aqueous humor and cerebrospinal fluid formation. In: Barriers and Fluids of the Eye and Brain Segal, MB (edn), MacMillan Press, London.

11. Maren TH (1995) The development of topical carbonic anhydrase inhibitors. J Glaucoma 4: 49-62.

12. Barboiu M, Supuran CT, Menabuoni L, Scozzafava A, Mincione F, et al. (1999) Carbonic anhydrase inhibitors. Synthesis of topically effective intraocular pressure lowering agents derived from 5-(w-aminoalkylcarboxamido)-1,3,4thiadiazole-2- sulfonamide. J Enz Inhib 15: 23-46.

13. Celik U, Celik T, Avci A, Annagur A, Yilmaz HL, et al. (2009) Metabolic acidosis in a patient with type 1 diabetes mellitus complicated by methanol and amitriptyline intoxication. Eur J Emerg Med 16: 45-48.

14. Gunnerson KJ, Saul M, He S, Kellum JA (2006) Lactate versus non-lactate metabolic acidosis: a retrospective outcome evaluation of critically ill patients. Crit Care 10: R22.

15. Nguyen HB, Rivers EP, Knoblich BP, Jacobsen G, Muzzin A, et al. (2004) Early lactate clearance is associated with improved outcome in severe sepsis and septic shock. Crit Care Med 32: 1637-1642.

16. Yki-Järvinen $H$, Bogardus C, Foley JE (1990) Regulation of plasma lactate concentration in resting human subjects. Metabolism 39: 859-864.

17. Py G, Lambert K, Milhavet O, Eydoux N, Prefaut C, et al. (2002) Effects of streptozotocin induced diabetes on markers of skeletal muscle metabolism and monocarboxylate transporter 4 transporters. Metabolism 51: 807-813.

18. Enoki T, Yoshida $Y$, Hatta $H$, Bonen $A$ (2003) Exercise training alleviates MCT and MCT4 reductions in heart and skeletal muscles of STZ-induced diabetic rats. J Appl Physiol (1985) 94: 2433-2438.

19. Becker HM, Deitmer JW (2004) Voltage dependence of $\mathrm{H}+$ buffering mediated 
by sodium bicarbonate cotransport expressed in Xenopus oocytes. J Bio Chem 279: 28057-28062.

20. Becker HM, Deitmer JW (2008) Nonenzymatic proton handling by carbonic anhydrase II during $\mathrm{H}+$-lactate cotransport via monocarboxylate transporter 1. J Biol Chem 283: 21655-21667.

21. Verpoorte JA, Mehta S, Edsall JT (1967) Esterase activities of human carbonic anhydrases B and C. J Biol Chem 242: 4221-4229.

22. Parui R, Gambhir KK, Mehrotra PP (1991) Changes in carbonic anhydrase may be the initial step of altered metabolism in hypertension. Biochem Int 23 $779-789$

23. Dodgson SJ, Watford M (1990) Differential regulation of hepatic carbonic anhydrase isozymes in the streptozotocin-diabetic rat. Arch Biochem Biophys 277: 410-414.

24. Crawford SO, Hoogeveen RC, Brancati FL, Astor BC, Ballantyne CM, et al. (2010) Association of blood lactate with type 2 diabetes: the Atherosclerosis Risk in Communities Carotid MRI Study. Int J Epidemiol 39: 1647-1655.

25. Nicky K, Juan CM, Sean LM, Briana S, Tim C, et al. (2012) Methazolamide Is a New Hepatic Insulin Sensitizer That Lowers Blood Glucose In Vivo. Diabetes 61: 2146-2154.

26. Forbath N, Kenshole AB, Hetenyi G Jr (1967) Turnover of lactic acid in normal and diabetic dogs calculated by two tracer methods. Am J Physiol 212: 11791184.

27. De Meutter RC, Shreeve WW (1963) Conversion of DL-lactate-2-C14 or -3 C14 or pyruvate-2-C14 to blood glucose in humans: effects of diabetes, insulin, tolbutamide, and glucose load. J Clin Invest 42: 525-533

28. Dodgson SJ, Forster RE 2nd (1986) Inhibition of CA V decreases glucose synthesis from pyruvate. Arch Biochem Biophys 251: 198-204.

29. Bode AM, Foster JD, Nordlie RC (1994) Glycogenesis from glucose and ureagenesis in isolated perfused rat livers. Influence of ammonium ion norvaline, and ethoxyzolamide. J Biol Chem 269: 7879-7886.

30. Cao TP, Rous S (1978) Action of acetazolamide on liver pyruvate carboxylase activity, glycogenolysis and gluconeogenesis of mice. Int J Biochem 9: 603605.

31. Radziuk J, Zhang Z, Wiernsperger N, Pye S (1997) Effects of metformin on lactate uptake and gluconeogenesis in the perfused rat liver. Diabetes 46 : 1406-1413.

32. DeFronzo R, Golay A, Felber J (1985) Glucose and lipid metabolism in obesity and diabetes mellitus. In: J. Garrow, and D. Hallidaed (eds) Substrate and Energy Metabolism. Oxford University press, London, UK.

33. Wetzel P, Hasse A, Papadopoulos S, Voipio J, Kaila K, et al. (2001) Extracellular carbonic anhydrase activity facilitates lactic acid transport in rat skeletal muscle fibres. J Physiol 531: 743-756.

34. Becker HM, Hirnet D, Fecher-Trost C, Sültemeyer D, Deitmer JW (2005) Transport activity of MCT1 expressed in Xenopus oocytes is increased by interaction with carbonic anhydrase. J Biol Chem 280: 39882-39889.

35. Becker HM, Klier M, Deitmer JW (2010) Nonenzymatic augmentation of lactate transport via monocarboxylate transporter isoform 4 by carbonic anhydrase II. J Membr Biol 234: 125-135.

36. Svichar N, Chesler M (2003) Surface carbonic anhydrase activity on astrocytes and neurons facilitates lactate transport. Glia 41: 415-419.

37. Becker HM, Broer S, Deitmer JW (2004) Facilitated lactate transport by MCT1 when coexpressed with the sodium bicarbonate cotransporter (NBC) in Xenopus oocytes. Biophys J 86: 235-247.

38. Fulgencio JP, Kohl C, Girard J, Pégorier JP (2001) Effect of metformin on fatty acid and glucose metabolism in freshly isolated hepatocytes and on specific gene expression in cultured hepatocytes. Biochem Pharmacol 62: 439-446.

39. Consoli A, Nurjhan N (1990) Contribution of gluconeogenesis to overall glucose output in diabetic and nondiabetic men. Ann Med 22: 191-195.
40. Stumvoll M, Nurihan N, Perriello G, Dailey G, Gerich JE (1995) Metabolic effects of metformin in non-insulin-dependent diabetes mellitus. N Engl J Med 333: $550-554$

41. Lutz TA, Estermann A, Haag S, Scharrer E (2001) Depolarization of the liver cell membrane by metformin. Biochim Biophys Acta 1513: 176-184.

42. Otto M, Breinholt J, Westergaard N (2003) Metformin inhibits glycogen synthesis and gluconeogenesis in cultured rat hepatocytes. Diabetes Obes Metab 5: 189-194.

43. Kuhn B, Hennig M, Mattei P (2007) Molecular recognition of ligands in dipeptidyl peptidase IV. Curr Top Med Chem 7: 609-619.

44. Mooradian AD (2009) Dyslipidemia in type 2 diabetes mellitus. Nat Clin Pract Endocrinol Metab 5: 150-159.

45. Arbeeny CM, Nordin C, Edelstein D, Stram N, Gibbons N, et al. (1989) Hyperlipoproteinemia in spontaneously diabetic guinea pigs. Metabolism 38 895-900.

46. Biswas UK, Kumar A (2010) Study on Lipid Profile, Oxidation Stress and Carbonic Anhydrase Activity in Patients With Essential Hypertension. Journal of Clinical and Diagnostic Research 4: 3414-3420.

47. Botre F, Botre C (1991) Physiologic implication of carbonic anhydrase facilitated $\mathrm{CO}_{2}$ diffusion: coupling to other biometabolic processes. In: Botre $\mathrm{F}$ Gros G, Storey BT (eds) Carbonic Anhydrase from Biochemistry and Genetics to Physiology and Clinical Medicine. VCH Publishers Inc, Newyork, USA.

48. Higgins PJ, Bunn HF (1981) Kinetic analysis of the nonenzymatic glycosylation of hemoglobin. J Biol Chem 256: 5204-5208.

49. Lowrey CH, Lyness SJ, Soeldner JS (1985) The effect of hemoglobin ligands on the kinetics of human hemoglobin A1c formation. J Biol Chem 260: 11611 11618.

50. Gil H, Mata-Sagreda J, Schowen R (1991) Isotope Effects in the Nonenzymatic Glucation of Hemoglobin Catalyzed by Phosphate. Actual Fisico-quÃm Org 286-306.

51. Gil H, Vasquez B, Pena M, Uzcategui J (2004) Effect of Carbonate and Arsenate on the Kinetics of Glycation of Human Hemoglobin. J Phys Org Chem 17: $537-540$.

52. Gil H, Uzcategui J (1993) Isotope Effects in the Nonenzymatic Glycation of Hemoglobin Catalyzed by DPG. Actual FÃsico-quÃm Org 109-121.

53. Baynes JW, Thorpe SR, Murtiashaw MH (1984) Nonenzymatic glucosylation of lysine residues in albumin. Methods Enzymol 106: 88-98.

54. Allen DW, Schroeder WA Balog J (1958) Oberservations on the chromatographic heterogeneity of normal adult and fetal human hemoglobin A study on the effectstallization and chromatography on the heterogeneity and isoleucine content. J Am Chem Soc 80: 1628-1634.

55. Rahbar S, Paulsen E, Ranney MR (1969) Studies of Hemoglobins in patients with diabtes mellitus. Diabetes 1: 332

56. Speeckaert M, Van Biesen W, Delanghe J, Slingerland R, Wiecek A, et al.(2014) Are there better alternatives than haemoglobin A1c to estimate glycaemic control in the chronic kidney disease population?. Nephrol Dial Transplant 29: 2167-2177.

57. Luft FC (2001) Lactic acidosis update for critical care clinicians. J Am Soc Nephrol 12: S15-19.

58. Klier M, Fabian TA, Joachim WD, Holger MB (2014) Intracellular and Extracellular Carbonic Anhydrases Cooperate Non-enzymatically to Enhance Activity of Monocarboxylate Transporters. The Journal of Biological Chemistry. 289: 2765-2775

59. Halperin FA, Cheema-Dhadli S, Chen CB, Halperin ML (1996) Alkali therapy extends the period of survival during hypoxia: studies in rats. Am J Physiol 271 R381-387. 